\title{
Avaliação de Métodos para Recuperação de Pastagens de Braquiária no Agreste de Pernambuco. 1. Aspectos Quantitativos ${ }^{1}$
}

\section{Maria da Conceição Silva ${ }^{2}$, Mércia Virgínia Ferreira dos Santos ${ }^{3}$, José Carlos Batista Dubeux Jr. ${ }^{3}$, Mário de Andrade Lira ${ }^{4}$, Daniel Fernando Ydoyaga Santana ${ }^{2}$, Iderval Farias ${ }^{5}$, Venézio Felipe dos Santos 5}

\begin{abstract}
RESUMO - O experimento foi realizado com o objetivo de avaliar a resposta produtiva de uma pastagem degradada de Brachiaria humidicola (Rendle) Schweickt sob diferentes métodos de recuperação. O delineamento experimental foi blocos ao acaso com confundimento e em parcelas subdivididas, sendo a parcela principal representada pela combinação dos manejos com os níveis de adubação e as subparcelas pelos períodos de diferimento. Os tratamentos experimentais foram constituídos de quatro manejos de recuperação (sem preparo do solo, gradagem, gradagem + milho, plantio direto do milho), dois níveis de nitrogênio (0 e $100 \mathrm{~kg}$ de $\mathrm{N} / \mathrm{ha}$ ), dois níveis de fósforo (0 e $100 \mathrm{~kg}$ de $\mathrm{P}_{2} \mathrm{O}_{5} /$ ha) e diferentes períodos de diferimento (113, 156, 200 e 240 dias), perfazendo 64 tratamentos, com três repetições. Houve interação entre sistemas de manejo e a adubação fosfatada, sendo obtidos acúmulo de matéria seca (AMS) médios de 7,52; 1,68; 1,10 e 4,43 t/ha de B. humidicola, para o sistema sem preparo do solo, gradagem, gradagem + milho e plantio direto do milho, respectivamente. O maior período de diferimento elevou AMS, altura de planta, a participação da braquiária no AMS e diminuiu a participação de outras espécies (\%) no AMS e a área de solo descoberto (\%). Pastagens de B. humidicola em início de degradação cultivada em solo com baixa disponibilidade de fósforo podem ser recuperadas com um período de descanso associado à adubação fosfatada.
\end{abstract}

Palavras-chave: adubação fosfatada, adubação nitrogenada, Brachiaria humidicola, gradagem, plantio direto

\section{Evaluation of Methods to Recovery Degraded Pastures of Brachiaria in the Agreste Region of Pernambuco State. 1. Quantitative Aspects}

\begin{abstract}
The experiment was performed to evaluate the productive response of a degraded B. humidicola pasture to different pasture recovery methods. It was used a split-plot within a confounded randomized block design. The main plot was represented by the combination among managements and fertilization levels and the sub-plot by the deferred periods. The experimental treatments were four recovery managements (no-tillage, harrowing, harrowing + corn as a companion crop, notillage + corn as a companion crop), two levels of nitrogen ( 0 and $100 \mathrm{~kg} / \mathrm{ha}$ of $\mathrm{N})$, two levels of phosphorus ( 0 and $100 \mathrm{~kg} / \mathrm{ha}$ of $\mathrm{P}_{2} \mathrm{O}_{5}$ ) and, different periods of deferment (113, 156, 200 and 240 days), totalizing 64 treatments with three replications each one. It was found a significant interaction between recovery managements and $\mathrm{P}$ fertilization. The average dry matter accumulation (DMA) was 7.52; $1.68 ; 1.10$ and 4.43 t/ha of $B$. humidicola for no-tillage, harrowing, harrowing + corn as a companion crop, no-tillage + corn as a companion crop, respectively. The highest deferment period increased DMA, plant heigth and B. humidicola participation in the botanical composition, as well reducing percentage of other species in the DMA and percentage of uncovered soil. Brachiaria humidicola pastures at the initial degradation stage, grown in low available phosphorus soils, may be recovered using a deferment period associated to a phosphorus fertilization.
\end{abstract}

Key Words: P fertilization, $\mathrm{N}$ fertilization, Brachiaria humidicola, harrowing, no-tillage

\section{Introdução}

A falta de adaptação da espécie forrageira ao local cultivado, assim como a diminuição da fertilidade do solo, associada ao manejo inadequado da pastagem, pode promover o ressurgimento de plan- tas mais adaptadas, espécies geralmente consideradas invasoras em pastagens cultivadas. Além destes fatores, a utilização extrativista das pastagens acarreta redução da quantidade e da qualidade da forragem produzida, promovendo a degradação da pastagem.

\footnotetext{
${ }^{1}$ Parte da dissertação apresentada a UFRPE pela primeira autora. Trabalho financiado pelo BNB e realizado pelo acordo IPA-UFRPE. 2 Estudante de doutorado em Zootecnia-UFRPE (mcsilvaforragem@bol.com.br).

3 Professor da UFRPE e bolsista CNPq (mercia@ufrpe.br; dubeuxjr@yahoo.com).

${ }_{5}^{4}$ Pesquisador do IPA, bolsista do CNPq.

5 Pesquisador do IPA.
} 
A adoção de mesma lotação durante todo o ano é uma prática comum para maioria dos criadores da região nordeste, o que ocasiona utilização do pasto além da capacidade de suporte no período de estiagem, fato que contribui para acelerar o processo de degradação das pastagens.

Degradação de pastagem é um termo usado para designar um processo evolutivo de perda de vigor, de produtividade e da capacidade de regeneração natural de uma dada pastagem, tornando-a incapaz de sustentar os níveis de produção e qualidade exigidos pelos animais, e de superar os efeitos nocivos de pragas, doenças e plantas invasoras (Kichel et al., 1997).

Os sinais de degradação incluem declínio da produtividade, crescente aumento da presença de plantas invasoras - que gradualmente diminuem a capacidade de suporte das pastagens, inicialmente ocupando os espaços de solo deixados descobertos pelas gramíneas forrageiras, e depois dominando as áreas ainda ocupadas pelas mesmas (Dias Filho, 1998) - e redução no número de plantas novas originadas de ressemeadura natural (Macedo \& Zimmer, 1993; Macedo, 1995).

Objetivou-se, com este trabalho, avaliar métodos para recuperação de pastagem de Brachiaria humidicola, em diferentes períodos de diferimento, no agreste de Pernambuco.

\section{Material e Métodos}

O experimento foi conduzido na Fazenda Santa Inês, localizada em Sapucarana, município de Bezerros, no período de março a dezembro de 2000. Bezerros situa-se no agreste de Pernambuco, a $8^{\circ} 12^{\prime} 00^{\prime \prime}$ de latitude (S) e $35^{\circ} 49^{\prime} 00^{\prime \prime}$ de longitude (W.Gr), segundo a Fundação de Informações para o Desenvolvimento de Pernambuco (1982). O local experimental apresenta microclima e vegetação diferenciados do agreste e é classificado, segundo Lima (1970), como brejo de altitude de área subúmida ou hipoxerófila. Na Estação experimental do IPA de Caruaru-PE, situada, a aproximadamente, $15 \mathrm{~km}$ do experimento, registrou-se precipitação pluviométrica de $1300 \mathrm{~mm}$, em 2000.

O solo da área experimental foi classificado como Argissolo Amarelo Distrófico típico textura média/argilosa (Embrapa, 1999).

Foram formadas 16 amostras compostas de 48 subamostras do solo em cada parcela experimental, para realização da análise, antes da aplicação dos tratamentos. Essas amostras apresentaram valores médios de: $\mathrm{pH}=5,06, \mathrm{P}$ disponível $=1,33 \mathrm{mg} / \mathrm{kg}$, $\mathrm{Ca}=3,10 \mathrm{cmol}_{\mathrm{c}} / \mathrm{dm}^{3}, \mathrm{Mg}=0,74 \mathrm{cmol}_{\mathrm{c}} / \mathrm{dm}^{3}, \mathrm{Na}=0,06$ $\mathrm{cmol}_{\mathrm{C}} / \mathrm{dm}^{3}, \mathrm{~K}=0,31 \mathrm{cmol}_{\mathrm{C}} / \mathrm{dm}^{3}, \mathrm{Al}=0,21 \mathrm{cmol}_{\mathrm{C}} / \mathrm{dm}^{3}$, $\mathrm{H}=4,40 \mathrm{cmol}_{\mathrm{C}} / \mathrm{dm}^{3}, \mathrm{~V}=47,73 \%, \mathrm{~m}=4,75 \%$, PST $=$ $0,68 \%$, densidade global $=1,32 \mathrm{~g} / \mathrm{cm}^{3}$, densidade da partícula $=2,59 \mathrm{~g} / \mathrm{cm}^{3}$, porosidade $=49 \%$ e matéria orgânica $=1,70 \%$ na camada $0-20 \mathrm{~cm}$ de profundidade. Após a última avaliação da braquiária (240 dias), foram repetidas as análises do solo.

O experimento foi realizado em uma pastagem de B. humidicola estabelecida há 20 anos, onde se observou a presença de diferentes espécies vegetais (Tabela 1) e áreas de solo descoberto. No herbário da Empresa de Pesquisa Agropecuária de Pernambuco (IPA), identificaram-se 11 famílias, 13 gêneros e 13 espécies, classificando as plantas segundo Cronquist (1981) (Tabela 1). Além das características da pastagem supracitada, abaixo de 70\% de participação da espécie cultivada, existe o processo de degradação (Nascimento Jr. et al., 1994).

O delineamento experimental foi o de blocos incompletos com confundimento parcial (Benza, 1954) da interação tripla (sistema de manejo x adubação nitrogenada $\mathrm{x}$ adubação fosfatada) e em parcelas subdivididas, em que a parcela principal foi representada pela combinação dos fatores manejo, nitrogênio e fósforo e as subparcelas, pelos períodos de diferimento.

Os tratamentos foram representados por quatro sistemas de manejo (sem preparo do solo, gradagem, gradagem + milho e plantio direto do milho), dois níveis de adubação nitrogenada (0 e 100 kg/ha de N), dois níveis de adubação fosfatada (0 e $100 \mathrm{~kg} / \mathrm{ha}$ de $\left.\mathrm{P}_{2} \mathrm{O}_{5}\right)$ e quatro períodos de diferimento $(113,156,200$ e 240 dias), perfazendo um total de 64 tratamentos, com três repetições. A gradagem foi realizada com grade aradora e niveladora, sendo idêntica nos tratamentos gradagem e gradagem + milho. As parcelas experimentais foram representadas por áreas de $40 \mathrm{~m}^{2}$

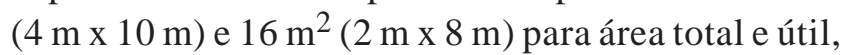
respectivamente, e as subparcelas, por áreas de metros quadrados. Havia um espaçamento de seis metros entre parcelas e dois metros entre blocos, perfazendo uma área total de $4.608 \mathrm{~m}^{2}$, sendo os blocos alocados em curvas de nível.

No início do experimento, foi realizado pastejo de uniformização, deixando-se um resíduo com altura aproximada de cinco centímetros, sendo posteriormente aplicados os tratamentos no início do período chuvoso. 
Tabela 1 - Espécies botânicas presentes na área e composição botânica inicial da área experimental Table 1 - Botanical species found and initial botanical composition of the experimental area

\begin{tabular}{|c|c|c|c|}
\hline $\begin{array}{l}\text { Família } \\
\text { Family }\end{array}$ & $\begin{array}{l}\text { Nome científico } \\
\text { Scientific name }\end{array}$ & $\begin{array}{l}\text { Nome vulgar } \\
\text { Common name }\end{array}$ & $\begin{array}{c}\text { Participação } \\
\text { Participation (\%) }\end{array}$ \\
\hline Gramineae & Brachiaria humidicola (Rendle) Schweickt & Braquiária 409 & 67,13 \\
\hline Rubiaceae & Borreria verticillata (L.) G. F. W. Meyer & Vassourinha de botão & 6,69 \\
\hline Rubiaceae & Borreria latifolia (Aubl.) Schum & Rama verde & 3,12 \\
\hline Oxilidaceae & Oxalis sp. & Flor amarela & 1,62 \\
\hline Mimosaceae & Mimosa sensitiva L. & Malícia de boi & 0,13 \\
\hline Euphorbiaceae & Croton campestris St. Hil. & Velame & $21,31^{*}$ \\
\hline Fabaceae & Desmodium adscendens D.C. & Carrapicho beiço de boi & \\
\hline Gramineae & Brachiaria decumbens Stapf & Braquiária de alto & \\
\hline Passifloraceae & Passiflora sp. & Maracujá do mato & \\
\hline Solanaceae & Solanum stipulaceum Willd et Roem \& schult & Jurubeba & \\
\hline Turniraceae & Piriqueta racemosa (Jacq.) Sw. & Semente rajada & \\
\hline Turniraceae & Turnera calyptrocarpa Urban & Chanana & \\
\hline Verbenaceae & Lantana sp. & Câmara & \\
\hline Violaceae & Hybanthus calceolaria (L.) G. K. Schult & Poaia & \\
\hline
\end{tabular}

* Participação (\%): Ervas e arbustos - 10,81, gramíneas - 7,00 e leguminosas - 3,50.

* Participation (\%): Herbs and shrubs -10.81 , grasses -7.00 and legumes -3.50 .

O solo recebeu apenas adubações nitrogenada e fosfatada, sendo a última aplicada de uma única vez (superfosfato triplo) antes da aplicação dos sistemas de manejo. Quanto à adubação nitrogenada (uréia), aplicou-se $50 \%$ junto à adubação fosfatada e o restante após 30 dias. A adubações foram realizadas a lanço em toda área da parcela experimental, tanto nos tratamentos com plantio de milho como nos demais tratamentos que receberam adubação.

O milho var. São José foi plantado em quatro sementes/cova com manutenção de duas plantas/ cova, espaçadas $100 \mathrm{~cm}$ entre linhas e $40 \mathrm{~cm}$ entre plantas. Foi aplicado com pulverizador costal, 4 l/ha de Gesaprim (Atrazine) nas fileiras de milho, para evitar o surgimento de plantas concorrentes e 2 l/ha de Gramoxone (Paraquat) na Brachiaria referente ao tratamento com plantio direto.

Antes da aplicação dos tratamentos, estimouse disponibilidade de matéria seca e composição botânica da pastagem. A estimativa da composição botânica inicial foi realizada pelo método do peso seco escalonado, descrito por t'Mannetje \& Haydock, modificado por Jones \& Hargreaves (1979) e a estimativa de produção de matéria seca total, pelo método do rendimento comparativo, segundo Haydock \& Shaw (1975), ambas processadas pelo BOTANAL (Hargreaves \& Keer, 1978). As estimativas visuais foram feitas empregandose quadrados-amostras de $40 \mathrm{~cm}$ de lado, com 20 observações por parcela.

\footnotetext{
R. Bras. Zootec., v.33, n.6, p.1999-2006, 2004 (Supl. 2)
}

As avaliações referentes aos períodos de vedação foram realizadas nos dias 21/08, 03/10, 17/11 e 27/12/ 2000, correspondendo a 113, 156, 200 e 240 dias de diferimento, quando se determinou altura de planta, acúmulo de matéria seca (AMS), porcentagem de outras espécies (POE) e porcentagem de solo descoberto (PSD).

A altura de planta foi medida com o uso de uma régua graduada, determinando-se a altura média do dossel em cada tratamento experimental. $\mathrm{O}$ acúmulo de matéria seca (AMS) foi determinado adotando-se o método do corte em toda área da subparcela (dois metros quadrados) a, aproximadamente, cinco centímetros do nível do solo.

Foram empregados dois quadrados-amostra com $40 \mathrm{~cm}$ de lado/subparcela, para determinação da porcentagem de solo descoberto (PSD) por meio de observações visuais e para determinação da composição botânica do pasto.

A composição botânica foi determinada após présecagem do material, que foi separado em duas frações: Brachiaria e outras espécies, sendo a última utilizada para determinação da porcentagem de outras espécies.

O milho foi colhido aos 129 dias de crescimento, quando o mesmo estava no estádio farináceo duro, para determinação da produção de matéria seca, por se tratar de uma variedade tardia (var. São José).

Os dados obtidos foram analisados por corte e o conjunto dos resultados, considerando os períodos de diferimento, pelo programa estatístico SWNTIA (Embrapa, 1996). 


\section{Resultados e Discussão}

No início do período experimental, foram encontrados valores de 1,28 t/ha, 36,77\% e 7,90 cm, referentes à disponibilidade de matéria seca, ao percentual de solo descoberto e à altura do pasto de Brachiaria humidicola, respectivamente. Vale ressaltar que, antes da aplicação dos tratamentos, foi realizado um pastejo de uniformização.

Não houve diferença significativa $(\mathrm{P}>0,05)$ entre os tratamentos para as características químicas, densidade e porosidade das análises do solo no final do experimento, apresentando os seguintes valores médios: $\mathrm{pH}=5,31$, P disponível = 1,64 mg $/ \mathrm{kg}, \mathrm{Ca}=1,15 \mathrm{cmol}_{\mathrm{c}} / \mathrm{dm}^{3}$, $\mathrm{Mg}=0,66 \mathrm{cmol}_{\mathrm{c}} / \mathrm{dm}^{3}, \mathrm{Na}=0,03 \mathrm{cmol}_{\mathrm{c}} / \mathrm{dm}^{3}, \mathrm{~K}=$ $0,22 \mathrm{cmol}_{\mathrm{c}} / \mathrm{dm}^{3}, \mathrm{Al}=0,24 \mathrm{cmol}_{\mathrm{c}} / \mathrm{dm}^{3}, \mathrm{H}=4,05 \mathrm{cmol}_{\mathrm{c}}{ }^{\prime}$ $\mathrm{dm}^{3}, \mathrm{~V}=32,34 \%$, PST $=0,48 \%$, densidade global $=1,50 \mathrm{~g} / \mathrm{cm}^{3}$, densidade da partícula $=2,70 \mathrm{~g} / \mathrm{cm}^{3} \mathrm{e}$ porosidade $=44,67 \%$ na camada $0-20 \mathrm{~cm}$ de profundidade. Vale ressaltar que a ausência de diferença significativa $(\mathrm{P}>0,05)$ entre os tratamentos para $\mathrm{o}$ teor de fósforo no solo provavelmente está relacionada à fixação do referido elemento. Neste sentido, Lobato et al. (1986) afirmam que os solos brasileiros apresentam alta capacidade de fixação de fósforo, comprometendo boa quantidade do fósforo aplicado, especialmente se for fonte solúvel.

Na Tabela 2, são apresentados os valores referentes ao acúmulo de matéria seca da Brachiaria humidicola. Houve interação significativa $(\mathrm{P}<0,05)$ entre sistemas de manejo e adubação fosfatada, sendo os melhores resultados encontrados na área sem preparo do solo, que apresentou aumento de 2,31 t/ha para acúmulo de matéria seca quando adubada com fósforo. O efeito da adubação fosfatada também foi observado por Gatiboni et al. (2000), em pastagem natural.

A análise por corte para acúmulo de matéria seca revelou resultados semelhantes aos dados analisados conjutamente, entretanto, a adubação fosfatada não apresentou efeito significativo $(\mathrm{P}<0,05)$ aos 200 dias de diferimento para o sistema sem preparo do solo e aos 156 e 200 dias no plantio direto do milho.

Tabela 2 - Acúmulo de matéria seca (AMS) da B. humidicola, conforme os tratamentos experimentais Table 2 - Dry matter accumulation (DMA) of B. humidicola, according to the experimental treatments

\begin{tabular}{|c|c|c|c|c|c|c|}
\hline \multirow[t]{2}{*}{$\begin{array}{l}\text { Sistemas de manejo } \\
\text { Management systems }\end{array}$} & \multirow{2}{*}{$\begin{array}{l}\text { Adubação (kg/ha } \\
\text { Fertilization } \\
\mathrm{P}_{2} \mathrm{O}_{5}\end{array}$} & \multicolumn{4}{|c|}{$\begin{array}{l}\text { Período de diferimento (dias) } \\
\text { Deferement period(days) }\end{array}$} & \multirow[t]{2}{*}{$\begin{array}{l}\text { Média geral } \\
\text { General mean }\end{array}$} \\
\hline & & 113 & 156 & 200 & 240 & \\
\hline & \multicolumn{6}{|c|}{$\begin{array}{l}\text { AMS (t/ha) } \\
\text { DMA }(t / h a)\end{array}$} \\
\hline $\begin{array}{l}\text { Sem preparo do solo (No-tillage) } \\
\text { Sem preparo do solo (No-tillage) }\end{array}$ & $\begin{array}{c}0 \\
100\end{array}$ & $\begin{array}{l}2,93 b \\
4,65 a\end{array}$ & $\begin{array}{l}5,09 \mathrm{~b} \\
7,92 \mathrm{a}\end{array}$ & $\begin{array}{l}6,15 \mathrm{a} \\
7,93 \mathrm{a}\end{array}$ & $\begin{array}{l}6,65 b \\
9,55 a\end{array}$ & $\begin{array}{l}5,21 \mathrm{Ab} \\
7,52 \mathrm{Aa}\end{array}$ \\
\hline $\begin{array}{l}\text { Gradagem (Arrowing) } \\
\text { Média (Mean) }\end{array}$ & 0 & 0,30a & $1,12 \mathrm{a}$ & $1,47 a$ & 2,13a & 1,25Ca \\
\hline Gradagem(Arrowing) & 100 & 0,33a & $1,64 a$ & $2,06 a$ & $2,69 a$ & 1,68Ca \\
\hline $\begin{array}{l}\text { Gradagem + milho (Arrowing + corn) } \\
\text { Gradagem + milho (Arrowing + corn) }\end{array}$ & $\begin{array}{c}0 \\
100\end{array}$ & $\begin{array}{l}0,41 \mathrm{a} \\
0,43 \mathrm{a}\end{array}$ & $\begin{array}{l}1,02 \mathrm{a} \\
0,87 \mathrm{a}\end{array}$ & $\begin{array}{l}1,31 \mathrm{a} \\
1,31 \mathrm{a}\end{array}$ & $\begin{array}{l}1,73 a \\
1,81 a\end{array}$ & $\begin{array}{l}1,12 \mathrm{Ca} \\
1,10 \mathrm{Ca}\end{array}$ \\
\hline $\begin{array}{l}\text { Plantio direto do milho (No-tillage }+ \text { corn }) \\
\text { Plantio direto do milho (No-tillage }+ \text { corn })\end{array}$ & $\begin{array}{c}0 \\
100\end{array}$ & $\begin{array}{l}1,70 \mathrm{~b} \\
2,71 \mathrm{a}\end{array}$ & $\begin{array}{l}2,92 \mathrm{a} \\
4,18 \mathrm{a}\end{array}$ & $\begin{array}{l}3,17 \mathrm{a} \\
5,07 \mathrm{a}\end{array}$ & $\begin{array}{l}4,01 b \\
5,77 \mathrm{a}\end{array}$ & $\begin{array}{l}2,95 \mathrm{Bb} \\
4,43 \mathrm{Ba}\end{array}$ \\
\hline $\begin{array}{l}\text { Média geral (General mean) } \\
\text { CV }(\%) \\
\text { CVa }(\%) \\
\text { CVb }(\%)\end{array}$ & & $\begin{array}{l}1,68 \mathrm{D} \\
22,68\end{array}$ & $\begin{array}{l}3,09 \mathrm{C} \\
40,45\end{array}$ & $\begin{array}{c}3,55 \mathrm{~B} \\
30,66\end{array}$ & $\begin{array}{c}4,29 A \\
29,34\end{array}$ & \\
\hline $\begin{array}{l}\text { Sistemas de manejo (Management system) } \\
\text { Fósforo (Phosphorus) }\end{array}$ & & $\begin{array}{l}\text { NS } \\
\text { NS }\end{array}$ & $\begin{array}{l}\text { NS } \\
\text { NS }\end{array}$ & $\begin{array}{l}* \\
*\end{array}$ & $\begin{array}{l}\text { NS } \\
\text { NS }\end{array}$ & \\
\hline
\end{tabular}

Médias seguidas da mesma letra maiúscula na coluna, maiúscula em itálico na linha e minúscula na coluna dentro de cada sistema de manejo não diferem pelo teste Tukey, a $5 \%$ de probabilidade.

Means followed by the same letter, capital letter at the column, italic capital letter at the row and small letters within each management system, do not differ (P>.05), according to Tukey test.

* Efeito significativo $(P<0,05)$, NS Efeito não-significativo $(P>0,05)$.

* Significant effect $(P<.05)$, NS Not significant effect $(P>.05)$.

\section{R. Bras. Zootec., v.33, n.6, p.1999-2006, 2004 (Supl. 2)}


Apesar de a gradagem ser uma prática utilizada pelos produtores da região visando aumentar vigor da rebrota e produção em pastagens degradadas, Bonfim (2001) também observou aspecto negativo da gradagem como método de recuperação de pastagem em relação à produtividade.

Quanto às doses de fósforo dentro de cada sistema de manejo, apenas os tratamentos com gradagem não responderam positivamente, o que está associado à grande destruição das plantas de braquiária provocada por este processo (Carvalho et al., 1990), principalmente quando a gradagem é realizada de forma intensa, como no presente trabalho.

Em todos os períodos avaliados, o sistema sem preparo do solo apresentou maior $(\mathrm{P}<0,05)$ acúmulo de matéria seca e os tratamentos que receberam gradagem, menor. Resposta similar foi encontrada por Ydoyaga Santana (2002), trabalhando com braquiária no município de São João, no agreste pernambucano.
Quanto ao manejo com plantio direto do milho, a Brachiaria humidicola acumulou menos matéria seca que o sistema sem preparo do solo e mais que nas áreas gradeadas.

Observou-se crescente $(\mathrm{P}<0,05)$ acúmulo de matéria seca com o avanço do período de diferimento, porém com estabilidade na taxa de acúmulo de matéria seca (em kg/dia). Assim, torna-se relevante considerar outros parâmetros, como área de solo descoberto e participação de outras espécies na composição botânica da pastagem na determinação do período de diferimento a ser adotado como método de recuperação de pastagem.

Quanto à altura de planta de pastos rasteiros, como os de Brachiaria, por exemplo, pode-se afirmar que as alturas mais elevadas facilitam o pastejo e, conseqüentemente, o desempenho animal, e que, para uma mesma densidade de plantas, quanto maior a altura do pasto maior a produção de matéria seca do mesmo. Na Tabela 3, observa-se elevação $(P<0,05)$

Tabela 3 - Altura da B. humidicola, conforme os tratamentos experimentais

Table 3 - Plant height of B. humidicola, according the humidicola, according to the experimental treatments

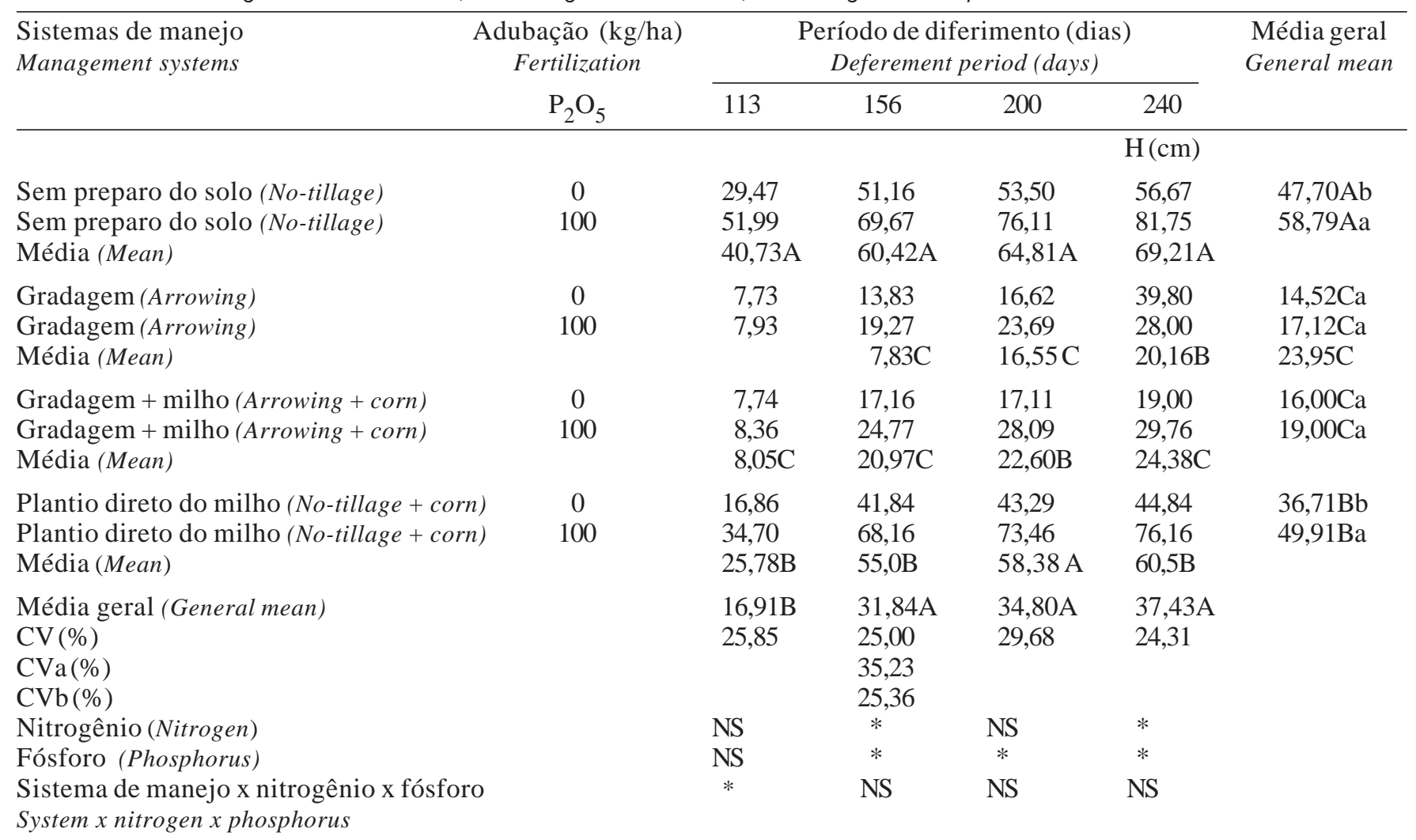

Médias seguidas da mesma letra maiúscula na coluna, maiúscula em itálico na linha e minúscula na coluna dentro de cada sistema de manejo não diferem pelo teste Tukey a $5 \%$ de probabilidade.

Means followed by the same letter, capital letter at the column, italic capital letter at the row and small letters within each management system, do not differ according to Tukey test $(P>05)$.

Efeito significativo $(P<0,05)$, NS Efeito não-significativo $(P>0,05)$.

Significant effect $(P<.05)$, NS Not significant effect $(P>.05)$.

R. Bras. Zootec., v.33, n.6, p.1999-2006, 2004 (Supl. 2) 
na altura no segundo período de diferimento, quando comparado ao primeiro, não sendo observado aumento significativo $(\mathrm{P}>0,05)$ a partir dos 156 dias de diferimento.

A análise por corte referente à altura de planta revelou superioridade $(\mathrm{P}<0,05)$ do manejo sem preparo do solo em relação aos demais tratamentos, exceto na terceira avaliação, em que o referido tratamento não diferiu $(\mathrm{P}>0,05)$ do sistema de plantio direto do milho.

Nas Tabelas 4 e 5, constam os resultados de percentual de solo descoberto e de participação de outras espécies na composição da pastagem, respectivamente, que não diferiram significativamente $(\mathrm{P}>0,05)$. $\mathrm{O}$ não preparo do solo promoveu menor $(\mathrm{P}<0,05)$ percentual de solo descoberto que nos demais sistemas de manejo, sendo as maiores áreas de solo descoberto encontradas nas áreas gradeadas, considerando as médias gerais. Contudo, a interação sistema de manejo x período de diferimento foi significativa, indicando comportamentos distintos quanto ao percentual de solo descoberto. Aos 156, 200 e 240 dias de diferimento, o sistema sem preparo do solo não diferiu do sistema de plantio direto, mas ambos tiveram menos solo descoberto que as áreas gradeadas.
A observação realizada aos 240 dias indicou que o tratamento gradagem apresenta menor porcentagem de solo descoberto que gradagem + milho. Contudo, este último resultado é de difícil explicação face o pequeno desenvolvimento da gramínea anual.

Além das melhores respostas encontradas no sistema sem preparo do solo, o mínimo ou nenhum revolvimento do solo promove a manutenção das características físicas do solo (Bayer et al., 1998).

A maior cobertura do solo, provavelmente, proporcionou maiores retenção de água e produção vegetal por área, inibindo o desenvolvimento de espécies indesejáveis, ao passo que, nas áreas gradeadas, ocorreu o inverso (Tabela 4).

Os sistemas de manejo sem preparo do solo e plantio direto do milho apresentaram melhor controle de outras espécies na pastagem, considerando a análise conjunta (Tabela 5). Os resultados por corte demonstraram que só houve diferença $(\mathrm{P}<0,05)$ para participação de outras espécies na pastagem a partir da segunda avaliação, ou seja, aos 156 dias de diferimento.

A parte aérea do milho apresentou produções de 0,$78 ; 1,63 ; 0,65$ e 1,76 t/ha de matéria seca, de acordo com os níveis de adubação $0 \mathrm{~kg}$ de $\mathrm{P}_{2} \mathrm{O}_{5}, 100 \mathrm{~kg}$ de

Tabela 4 - Porcentagem de solo descoberto (SD) na pastagem de B. humidicola, conforme os tratamentos experimentais

Table 4 - Percentage of uncovered soil (US) in pasture of B. humidicola, according the experimental treatments

\begin{tabular}{|c|c|c|c|c|c|}
\hline \multirow[t]{2}{*}{$\begin{array}{l}\text { Sistemas de manejo } \\
\text { Management systems }\end{array}$} & \multicolumn{4}{|c|}{$\begin{array}{l}\text { Período de diferimento (dias) } \\
\text { Deferement period(days) }\end{array}$} & \multirow[t]{2}{*}{$\begin{array}{l}\text { Média geral } \\
\text { General mean }\end{array}$} \\
\hline & 113 & 156 & 200 & 240 & \\
\hline \multicolumn{6}{|c|}{ SD (\%) (US, \%) } \\
\hline $\begin{array}{l}\text { Sem preparo do solo (No-tillage) } \\
\text { Gradagem (Arrowing) } \\
\text { Gradagem + milho (Arrowing + corn) } \\
\text { Plantio direto do milho (No-tillage }+ \text { corn) }\end{array}$ & $\begin{array}{l}1,77 \mathrm{C} \\
88,22 \mathrm{~A} \\
34,24 \mathrm{~B} \\
35,29 \mathrm{~B}\end{array}$ & $\begin{array}{l}4,25 \mathrm{~B} \\
55,42 \mathrm{~A} \\
67,50 \mathrm{~A} \\
17,17 \mathrm{~B}\end{array}$ & $\begin{array}{l}2,08 \mathrm{~B} \\
47,92 \mathrm{~A} \\
58,75 \mathrm{~A} \\
11,50 \mathrm{~B}\end{array}$ & $\begin{array}{r}0,83 \mathrm{C} \\
27,92 \mathrm{~B} \\
44,17 \mathrm{~A} \\
6,67 \mathrm{C}\end{array}$ & $\begin{array}{r}2,24 \mathrm{C} \\
54,87 \mathrm{~A} \\
51,16 \mathrm{~A} \\
17,66 \mathrm{~B}\end{array}$ \\
\hline $\begin{array}{l}\text { Média geral } \\
\text { General mean }\end{array}$ & 39,88a & $36,06 a$ & $30,06 b$ & $19,89 c$ & \\
\hline $\begin{array}{l}\mathrm{CV}(\%) \\
\mathrm{CVa}(\%) \\
\operatorname{CVb}(\%)\end{array}$ & \multicolumn{4}{|c|}{$\begin{array}{l}35,43 \\
23,88\end{array}$} & \\
\hline Fósforo (Phosphorus) & NS & NS & $*$ & NS & \\
\hline $\begin{array}{l}\text { Sistema de manejo x Fósforo } \\
\text { Management system x Phosphorus }\end{array}$ & $*$ & NS & NS & NS & \\
\hline $\begin{array}{l}\text { Nitrogênio x Fósforo } \\
\text { Nitrogen } x \text { Phosphorus }\end{array}$ & NS & $*$ & NS & NS & \\
\hline
\end{tabular}

Médias seguidas da mesma letra maiúscula na coluna e minúscula na linha não diferem pelo teste Tukey a 5\% de probabilidade.

Means followed by the same letter, capital letter at the column and small letters at the row do not differ according to Tukey test ( $P>0.05)$.

* Efeito significativo $(P<0,05)$, NS Efeito não significativo $(P>0,05)$.

* Significant effect $(P<.05)$, NS Not significant effect $(P>.05)$.

R. Bras. Zootec., v.33, n.6, p.1999-2006, 2004 (Supl. 2) 
Tabela 5 - Porcentagem de outras espécies (OE) na pastagem de B. humidicola, conforme os tratamentos experimentais

Table 5 - Percentage of other species in pasture of B. humidicola, according to the experimental treatments

\begin{tabular}{|c|c|c|c|c|c|}
\hline \multirow[t]{2}{*}{$\begin{array}{l}\text { Sistemas de manejo } \\
\text { Management systems }\end{array}$} & \multicolumn{4}{|c|}{$\begin{array}{l}\text { Período de diferimento (dias) } \\
\text { Deferement period(days) }\end{array}$} & \multirow[t]{2}{*}{$\begin{array}{l}\text { Média geral } \\
\text { General mean }\end{array}$} \\
\hline & 113 & 156 & 200 & 240 & \\
\hline \multicolumn{6}{|c|}{$\mathrm{OE}(\%)$} \\
\hline Sem preparo do solo (No-tillage) & $27,28 \mathrm{~A}$ & 17,72B & 21,07B & 15,09B & $20,29 B$ \\
\hline Gradagem (Arrowing) & $45,09 \mathrm{~A}$ & $51,84 \mathrm{~A}$ & $39,44 \mathrm{AB}$ & $35,39 \mathrm{AB}$ & $42,94 \mathrm{~A}$ \\
\hline Gradagem + milho (Arrowing + corn) & $43,02 \mathrm{~A}$ & $53,67 \mathrm{~A}$ & $48,55 \mathrm{~A}$ & $44,08 \mathrm{~A}$ & $47,33 \mathrm{~A}$ \\
\hline Plantio direto do milho (No-tillage + corn $)$ & $30,23 \mathrm{~A}$ & $19,49 \mathrm{~A}$ & 15,92B & 13,37B & $19,75 B$ \\
\hline Média geral (General mean) & $36,41 \mathrm{a}$ & $35,68 a$ & $31,24 a$ & $26,98 a$ & \\
\hline $\mathrm{CV}(\%)$ & 42,82 & 50,55 & 54,29 & 69,16 & \\
\hline $\mathrm{CVa}(\%)$ & 77,19 & & & & \\
\hline $\mathrm{CVb}(\%)$ & 43,03 & & & & \\
\hline
\end{tabular}

Médias seguidas da mesma letra maiúscula na coluna e minúscula na linha não diferem pelo teste Tukey a $5 \%$ de probabilidade. Means followed by the same letter, capital letter at the column and small letters at the row, do not differ ( $P>.05)$, according to Tukey test.

$\mathrm{P}_{2} \mathrm{O}_{5}, 0 \mathrm{~kg}$ de $\mathrm{N}$ e $100 \mathrm{~kg}$ de $\mathrm{N}$, respectivamente. $\mathrm{O}$ sistema de manejo do milho apresentou 1,48 t MS/ha, para área gradeada, valor superior $(\mathrm{P}<0,05)$ ao plantio direto, que produziu $0,93 \mathrm{t} \mathrm{MS} / \mathrm{ha}$. Ressalta-se que, no Centro-Sul, o cultivo do milho geralmente é no verão, quando, temperatura e luminosidades são mais altas, enquanto, no nordeste, é no inverno. Portanto, os fatores temperatura e luminosidade durante este trabalho proporcionaram ciclos mais longos.

A produção de espigas de milho foi quase insignificante, entretanto, observou-se aumento quando se aplicaram nitrogênio e fósforo simultaneamente, passando de $12 \mathrm{~kg} / \mathrm{ha}$ de MS e $75 \mathrm{~kg} / \mathrm{ha}$ de MS. Isso provavelmente ocorreu porque a eficiência na utilização de nitrogênio pelas plantas melhora com a presença do fósforo. Mesmo incluindo a produção do milho nos referidos sistemas de manejo, o tratamento sem preparo do solo continuou com a maior produção de matéria seca.

Inicialmente, não houve diferença entre tratamentos quanto ao número de plantas de milho/parcela. Porém, aos 129 dias esse número diminuiu consideravelmente $(\mathrm{P}<0,05)$ de 76 para 54 nas parcelas sem aplicação de $\mathrm{P}$, demonstrando a importância do fósforo para a sobrevivência do milho.

A baixa produção do milho pode estar associada a vários fatores, dentre eles ausência de calagem, baixo teor de matéria orgânica do solo e ausência de adubação com micronutrientes. Trabalho similar foi realiza- do por Ydoyaga Santana (2002) e resultou em produção zero do milho. Contudo, a utilização de culturas anuais na recuperação de pastagens degradadas no agreste de Pernambuco deve ser mais estudada.

\section{Conclusões}

O sistema sem preparo do solo, associado à adubação fosfatada, apresentou-se como método mais eficiente na recuperação de pastagem de B. humidicola.

Não foi observado efeito da adubação nitrogenada sobre o acúmulo de matéria seca da Brachiaria humidicola.

O processo de gradagem dificultou a rebrota do pasto, comprometendo a recuperação da pastagem de Brachiaria humidicola.

A pastagem apresentou resultados satisfatórios de recuperação aos 113 dias de diferimento.

\section{Agradecimento}

Ao pesquisador José Nilson de Melo (in memorian), pela ajuda e dedicação indispensáveis à realização de todas as atividades de campo. À Universidade Federal Rural de Pernambuco, à Empresa Pernambucana de Pesquisa agropecuária e ao Banco do Nordeste do Brasil, pelo apoio técnico e financeiro promovido. 


\section{Literatura Citada}

BAYER, C.; MIELNICZUK, J.; PAVINATO, A. Sistemas de manejo do solo e seus efeitos sobre o rendimento do milho. Ciência Rural, v.28, n.1, p.23-28, 1998.

BENZA, J.C. Experimentacion agricola con aplicacion a la ganaderia. Lima: Agro-Ganaderas, 1954. p.228-254.

BOMFIM, E.R.P. Tratamento físico associado à adubação na recuperação de pastagem degradada de braquiária. Lavras: Universidade Federal de Lavras, 2001. 100p. Dissertação (Mestrado em Zootecnia) - Universidade Federal de Lavras, 2001.

CARVALHO, S.I.C.; VILELA, L.; SPAIN, J.M. et al. Recuperação de pastagem degradadas de $B$. decumbens cv. Basilik na região dos Cerrados. Pasturas Tropicales, v.12, n.2, p.24-28, 1990.

CRONQUIST, A. An integrated sistem of classification of flowering plant. New York: Colombia University, 1981. $1262 p$.

DIAS FILHO, M.B. Pastagens cultivadas na Amazônia Oriental Brasileira: Processos e causas de degradação e estratégias de recuperação. In: DIAS, L.E.; MELLO, J.W.V. (Eds.) Recuperação de áreas degradadas. Viçosa, MG: Sociedade Brasileira de Recuperação de Àreas Degradadas, 1998. p.135-147.

EMPRESA BRASILEIRA DE PESQUISAS AGROPECUÁRIAS - EMBRAPA. Centro nacional de pesquisa de solos. Sistema brasileiro de classificação de solos. Brasília: Embrapa Produção de Informação. Rio de Janeiro: Embrapa Solos, 1999. 412p.

EMPRESA BRASILEIRA DE PESQUISAS AGROPECUÁRIAS - EMBRAPA. Centro Nacional de Pesquisa Tecnologica em Informática para a Agricultura. SWNTIA - Manual do usuário-Versão 4.2.1. Campinas:, 1996. “não paginado”.

FUNDAÇÃO DE INFORMAÇÕES PARA DESENVOLVIMENTO DE PERNAMBUCO. Informações municipais: bezerros. Recife. “não paginado”. 1982.

GATIBONI, L.C.; KAMINSKI, J.; PELLEGRINI, J.B.R. Influência da adubação fosfatada e da introdução de espécies forrageiras de inverno na oferta de forragem de pastagem natural. Pesquisa Agropecuária Brasileira, v.35, n.8, p.1663-1668, 2000.

HARGREAVES, J.N.G.; KEER, J.D. BOTANAL - A comprehensive sampling and computing procedure for estimating pasture yield and composition. II. Computational package. Tropical agronomy technical memoradum. 9. St. Lúcia, CSIRO - Division of tropical crops and pastures, 1978. 88p.
HAYDOCK, K.P.; SHAW, N.H. The comparative yield method of estimating dry matter yield of pasture. Austrralian Journal of Experimental Agriculture and Animal Husbandry, v.15, n.76, p.663-670, 1975.

JONES, R.M.; HARGREAVES, J.N.G. Improvements to the dry-weight-rank method of measuring botanical composition. Grass Forage Science, v.34, n.2, p.181-189, 1979.

KICHEL, A.N.; MIRANDA, C.H.B.; ZIMMER, A.H. Fatores de degradação de pastagem sob pastejo rotacionado com ênfase na fase de implantação. In: SIMPÓSIO SOBRE MANEJO DA PASTAGEM, 1997, Piracicaba. Anais... Piracicaba: Fundação de Estudos Agrários Luiz de Queiroz, 1997. p.193-211.

LOBATO, E.; KORNELIUS, E.; SANZONOWICZ, C. Adubação fosfatada em pastagens. In: SIMPÓSIO SOBRE CALAGEM E ADUBAÇÃO DE PASTAGENS, 1., 1985, Nova Odessa. Anais... Piracicaba: Associação Brasileira para Pesquisa da Potássio e do Fosfato, 1986. p.145-174.

MACEDO, J. Os cerrados brasileiros: alternativas para a produção de alimentos no limiar do século XXI. Revista de Política Agrícola, v.4, n.2, p.11-18, 1995.

MACEDO, M.C.; ZIMMER, A.H. Sistema planta/lavouras e seus efeitos na produtividade agropecuária. In: SIMPÓSIO SOBRE ECOSSISTEMA DE PASTAGEM, 2., 1993, Jaboticabal. Anais... Jaboticabal: Universidade Estadual Paulista, 1993. p.216-245.

NASCIMENTO JR., D.; QUEIROZ, D.S.; SANTOS, M.V.F. Degradação das pastagens e critérios para avaliação. In: SIMPÓSIO SOBRE MANEJO DAS PASTAGENS, 11., 1994, Piracicaba. Anais... Piracicaba: Fundação de Estudos Agrários Luiz de Queiroz, 1994. p.107-152.

YDOYAGA SANTANA, D.F. Pastagens degradadas no Agreste Pernambucano: métodos de recuperação. Recife: Universidade Federal Rural de Pernambuco, 2002. 59p. Dissertação (Mestrado em Zootecnia) - Universidade Federal Rural de Pernambuco, 2002.

Recebido em: 08/09/03 Aceito em: 05/07/04 